ARTIGO

\title{
As relações entre família, escola e violência à luz da teoria bioecológica
}

\author{
The relationship between family, school and violence in the light of bioecological \\ theory
}

Michelle Popenga Geraim MONTEIRO*

https://orcid.org/oooo-0003-3058-8987

\section{Tatiane Delurdes de LIMA-BERTON**}

https://orcid.org/oooo-00o1-6653-2593

Araci ASINELLI-LUZ ${ }^{* * *}$

https://orcid.org/oooo-001-5880-0543

Resumo: Este artigo discute a relação da violência na família e escola e a influência no desenvolvimento da criança. O tema é abordado na perspectiva Bioecológica do desenvolvimento humano e se baseia em revisão de literatura. Muitos são os autores que contribuíram para a discussão do tema. O estudo ressalta que tanto a família como a escola são contextos permeados por relações de conflito e violência, com repercussão na vida da criança. Em se tratando de desenvolvimento humano, compreender como a violência se instala e se manifesta no mesossistema família-escola auxilia no estímulo a políticas públicas de prevenção da violência com crianças e adolescentes.

Palavras-chave: Violência. Vida familiar. Espaço escolar. Bioecologia. Relações Sociais.

Abstract: This article discusses the relationship between violence in the family and school, and its influence on the child's development. The theme is approached from the bioecological perspective of human development and is based on a literature review. Many authors contributed to the discussion of the topic. The study highlights that both the family and school are contexts permeated by relationships of conflict and violence, with repercussions for the child's life. In dealing with human development, understanding how violence occurs and manifests itself in the family-school mesosystem helps to stimulate public policies for preventing violence among children and adolescents.

Keywords: Violence. Family life. School space. Bioecology. Social relationships.

Submetido em: 19/6/2020. Revisado em: 7/10/2020. Aceito em: 3/11/2020.

\footnotetext{
*Pedagoga. Doutoranda em Educação pela Universidade Federal do Paraná. (UFPR, Curitiba, Brasil). Rua Rockfeller, 57. Bolsista CAPES. E-mail: mizinhadobru@yahoo.com.br.

** Pedagoga. Doutoranda em Educação pela Universidade Federal do Paraná. (UFPR, Curitiba, Brasil). Rua Rockfeller, 57. Bolsista CAPES. E-mail: tati8lima@gmail.com.

*** Professora Adjunta. Doutora em Educação pela Universidade de São Paulo. Professora da Universidade Federal do Paraná. (UFPR, Curitiba, Brasil). Rua Rockfeller, 57. E-mail: araciasinelli@gmail.com.
}

"O presente trabalho foi realizado com apoio da Coordenação de Aperfeiçoamento de Pessoal de Nível Superior - Brasil (CAPES) - Código de Financiamento 001". copiar e redistribuir o material em qualquer suporte ou formato, bem como adaptar, transformar e criar a partir deste material para qualquer fim, mesmo que comercial. O licenciante não pode revogar estes direitos desde que você respeite os termos da licença. 


\section{Introdução}

escola e a família são os dois microssistemas de desenvolvimento fundamentais
na construção do ciclo vital do ser humano e possuem relação estreita. Ambas
fazem parte da transmissão e construção do conhecimento culturalmente organizado, atuando como alavancas para o desenvolvimento de habilidades no processo do desenvolvimento humano, já que "[...] o sentido etimológico da palavra educar significa promover, assegurar o desenvolvimento de capacidades físicas, intelectuais e morais, sendo que, de forma geral, tal tarefa tem sido de responsabilidade dos pais" (OLIVEIRA; MARINHO-ARAÚJO, 2010 p. 100).

A integração entre a escola e família (mesossistema ${ }^{1}$ ) para o desenvolvimento pleno da criança vem ganhando destaque entre pesquisadores da área no campo da Educação (POLONIA; DESSEN, 2005; 2007; DE ANTONI; KOLLER, 2010; SOUZA, 2017), considerando que esses dois contextos estão muito presentes na vida social, emocional, psicológica e estudantil da criança. Elas se complementam em funções, contribuindo para o desenvolvimento humano e, portanto, para a formação do cidadão e uma precisa da outra para que, juntas, auxiliem nos processos de evolução dos sujeitos (DESSEN; POLONIA, 2007; DE ANTONI; KOLLER, 2010; MARCONDES; SIGOLO, 2012; SOUZA, 2017).

Os cuidados de ambos os microssistemas (família e escola) são diferenciados, mas culminam para o bem comum: o desenvolvimento humano. A função da família é basicamente o cuidado e proteção, incitando a formação do sujeito para a sobrevivência humana, através do aprendizado de valores culturais enraizados no meio em que vive. Já na escola, o destaque é para a formação acadêmica e da cidadania - o ensino e aprendizagem dos conteúdos acumulados ao longo da história e sua vivência na sociedade (DESSEN; POLONIA, 2007; DE ANTONI; KOLLER, 2010; MARCONDES; SIGOLO, 2012; SOUZA, 2017).

Entretanto, no mesossistema escola e família ganha destaque o tema violência, que está presente no cotidiano de muitas crianças. Abusos físicos, verbais e negligência fazem parte da vida de muitos indivíduos no período da infância e adolescência em suas relações familiares, o que acaba por refletir em sua dinâmica escolar (DESSEN; POLONIA, 2007; DE ANTONI; KOLLER, 2010; MARCONDES; SIGOLO, 2012; SOUZA, 2017).

Para o presente artigo, assume-se a dimensão humanizadora de prevenção, indicandoa como processo de conhecimento, crescimento e desenvolvimento do ser humano como um todo, enfatizando a criança e as suas condições biopsicossociais, em universos históricos, políticos, econômicos e sociais, refletindo, principalmente, sobre o desenvolvimento humano sadio. O objetivo é destacar a importância da família e da escola na condição de sistemas bioecológicos em interação permanente, bem como as situações de violência (sejam elas físicas - incluindo o bullying escolar -, psicológicas, morais, estruturais ou sociais) e suas implicações no desenvolvimento da criança à luz

${ }^{1}$ Mesossistema refere-se ao conjunto família e escola que se manifestam em uma relação de interdependependência.

Argum., Vitória, v. 12, n. 3, p. 211-221, set./dez. 2020. | ISSN 2176-9575 
da Teoria Bioecológica de Urie Bronfenbrenner (2011), que concebe o desenvolvimento do ser humano como produto da interação com o ambiente e seus contextos em um determinado tempo. Por isso, trata-se de um estudo bibliográfico e descritivo, destacando a relevância do estudo na área educacional que se justifica em razão da produção de conhecimento no campo teórico-metodológico para a comunidade escolar e científica, como forma de reflexão sobre as relações sociais, além de tornar-se um meio de suscitar discussões entre sociedade acadêmica e demais agentes inseridos no campo da educação.

\section{Família, escola e violência}

A família é o primeiro microssistema que a criança tem contato e é onde ocorrem as primeiras interações sociais. Por meio do contato com os pais ou cuidadores, a criança aproxima-se dos primeiros conceitos, regras e valores que contribuirão para o seu desenvolvimento (DESSEN; POLONIA, 2007; DE ANTONI; KOLLER, 2010; MARCONDES; SIGOLO, 2012; SOUZA, 2017). No espaço familiar, a criança desenvolve as habilidades sociais e emocionais com as quais irá manifestar-se ao longo de sua vida. Para a família, cabe a responsabilidade junto às crianças, de orientar o desenvolvimento e a aquisição de comportamentos considerados adequados, em termos dos padrões sociais vigentes em determinada cultura. Entretanto, a violência faz parte do cotidiano de muitas pessoas, mesmo em seu ambiente doméstico (OLIVEIRA; MARINHO-ARAÚJO, 2010; LOURENÇO; SENRA, 2012; SILVA, et. al., 2011).

Urie Bronfenbrenner (2011) desenvolveu sua Teoria Bioecológica do Desenvolvimento Humano tendo como um dos princípios fundamentais a família, baseando-se nessa interação como um sistema complexo que influencia e sofre influências de ambientes externos. Essa teoria afirma que, ao longo do ciclo vital, ocorrem "[...] mudanças nas características biopsicológicas dos seres humanos, tanto no indivíduo como no grupo. Esse processo estende-se pelo ciclo vital, pelas gerações, pela história passada e futura, sendo o desenvolvimento compreendido como contínuo e processual" (DE ANTONI; KOLLER, 2010 p. 20).

O modelo bioecológico do desenvolvimento humano enfatiza a instituição familiar como um ambiente rico de interações afetivas, sociais, hierárquicas, culturais, morais, éticas e de alteridade. Embora possam existir fatores de risco (alcoolismo parental, violência doméstica, uso de drogas, desemprego, conflitos familiares, perdas importantes, entre outros), a presença de fatores de proteção (afeto, respeito, gestão do cuidado, interações harmoniosas, valores morais, espiritualidade etc.) podem se sobressair e, com isso, minimizar as influências negativas, mesmo na presença de fatores de risco. Ou seja, a família torna-se um ambiente propício para o desenvolvimento da resiliência.

A violência familiar que ocorre entre seus pares (pais, filhos, avós) tem ganhado destaque em estudos voltados à saúde pública brasileira, onde maus-tratos, em especial os abusos físicos e a negligência na infância e adolescência, atingem altas taxas. "No Brasil, é possível estimar que 600 mil crianças e adolescentes sejam vítimas 
de diversas formas de violência doméstica (VD) e/ou intrafamiliar" (LOURENÇO; SENRA, 2012 p. 44-45). Esse fato se torna expressivo se comparado a outras realidades.

O ambiente familiar e as relações que são estabelecidas por meio dele influenciam e favorecem os comportamentos nas crianças. Assim, se o ambiente familiar é violento, a criança tende a reproduzir na escola, entre seus pares (validade ecológica), essas atitudes violentas que sofre em sua casa, $\mathrm{O}$ modelo educativo familiar violento pode influenciar, com maior ou menor intensidade, atitudes violentas entre as crianças, como por exemplo, os maus-tratos dentro da família, métodos educativos ambíguos, a estruturação familiar inadequada e a falta de tempo dos pais para os filhos (FANTE, 2005; UNESCO, 2019). Concorda-se com Fante (2005) e Silva (2010) ao afirmarem que as situações que mais provocam situações violentas futuras são os castigos físicos e verbais e os maus-tratos psicológicos, pois afetam a estrutura cerebral da criança, fazendo com que ela se sinta desprotegida e desvalorizada. "Os praticantes do bullying com frequência têm problemas subjacentes; aqueles que cometem o bullying o fazem devido à frustração, humilhação, raiva ou para obter status social" (UNESCO, 2019, p. 20). Segundo o relatório sobre Violência escolar e Bullying (UNESCO, 2019) esses processos acarretam numa infância conturbada, abusiva (no caso da criança se tornar um agressor) ou passiva demais (a criança reprime o que passou e se torna frágil e submissa), repercutindo com veemência em sua aprendizagem acadêmica, na vida pessoal e social, conforme os estudos de Fante (2005), Lopes Neto (2005), Silva (2010), Souza (2016) e Monteiro (2017).

\begin{abstract}
Análises de avaliações internacionais de aprendizagem salientam o impacto do bullying nos resultados de aprendizagem. Elas mostram claramente que o bullying reduz o desempenho dos estudantes em matérias essenciais como a matemática, e outros estudos também documentaram um impacto negativo da violência escolar e do bullying no rendimento escolar [...]. As crianças e adolescentes que sofrem bullying são mais propensos a terem dificuldades interpessoais, a se sentirem deprimidos, solitários ou ansiosos, a terem baixa autoestima, pensamentos suicidas ou a tentarem o suicídio. A violência escolar e o bullying também afetam a saúde mental e emocional dos agressores e das testemunhas (UNESCO, 2019, p. 27- 28).
\end{abstract}

Além da família, a escola é considerada um contexto significativo de influência na vida da criança e do adolescente. Nela, a pessoa em fase de escolarização (criança, adolescente, jovem, adulto ou idoso) fará interações sociais com seus pares e professores. A função da escola é a de socialização do saber cultural sistematizado e acumulado ao longo dos anos, fornecendo as condições aos estudantes de superarem as dificuldades, contribuindo para os processos de desenvolvimento do indivíduo. Nesse sentido, a escola é “[...] um contexto diversificado de desenvolvimento e aprendizagem, isto é, um local que reúne diversidade de conhecimentos, atividades, regras e valores e que é permeado por conflitos, problemas e diferenças" (DESSEN; POLONIA, 2007 p. 25). É na escola que se podem observar questões voltadas à socialização, uma vez que o estudante interage com seus pares, expressando suas atitudes e opiniões.

O tema violência escolar tem sido alvo de preocupações na sociedade atual devido ao seu aumento exponencial e significativo. "Estima-se que, todos os anos, 246 milhões de 
crianças e adolescentes sofrem algum tipo de violência escolar e bullying" (UNESCO, 2019, p. 9). Nesse estudo a violência escolar refere-se a todos os comportamentos violentos e antissociais, incluindo os conflitos entre pares (bullying), danos ao patrimônio, atos criminosos, entre outros, que ocorrem no microssistema escola (LOPES NETO, 2005). Sua presença, em muitos casos, depende de fatores externos, os denominados fatores de risco relativos às relações familiares inadequadas, muito comuns entre crianças e adolescentes em idade escolar, bem como os fatores ligados à vulnerabilidade ambiental, cultural e estrutural da sociedade onde a escola se encontra (FANTE, 2005; OLIVEIRA; MARINHO-ARAÚJO, 2010; LOURENÇO; SENRA, 2012).

O comportamento violento na escola causa preocupação e é resultado da interação entre um sujeito em desenvolvimento e os contextos sociais (micro e mesossistemas) ao qual ele se depara ao longo dos tempos, como a família, a escola e a sua comunidade. As manifestações de violências que se observam nas escolas, de certo modo, reproduzem os modelos de interações desrespeitosas e de intolerância observadas no mundo contemporâneo, causando sofrimento e medo (LOPES NETO, 2005; FANTE, 2005; ANTUNES; ZUIN, 2008; BRONFENBRENNER, 2011).

As pesquisas que têm como temática o fenômeno da violência, na perspectiva da educação em Direitos Humanos (UNESCO, 2019; SALLES FILHO, 2019) e da prevenção da violência, tendem a contribuir com a desnaturalização da escola como ambiente em que sejam comuns ou naturais os casos de violência. A possível representação social da escola como reprodutora da sociedade deve ser modificada, compreendendo a escola como microssistema relevante de transformação social e local de ampliação da Cultura de Paz e da Educação para a Paz.

Para compreender o complexo mesossistema família-escola e seus impactos é preciso lembrar de que a família e a escola, na condição de microssistemas, existem em interdependência. Nota-se, por exemplo, que contextos de violência intrafamiliar podem contribuir para baixo rendimento escolar, comportamentos agressivos, evasão e reprovação. A dinâmica familiar tem impacto na vida estudantil dos alunos. Embora a escola faça parte de um sistema imbricado que auxilie para a mudança de comportamentos agressivos, faz-se necessária a contribuição de outros contextos, como a família, para apoio na aprendizagem da criança (DESSEN; POLONIA, 2007). Bronfenbrenner (2011) faz um alerta: "O coração de nosso sistema social é a família. Se quisermos manter a saúde da nossa sociedade, temos de descobrir a melhor forma de proteger este coração" (BRONFENBRENNER, 2011, p. 278).

A escola como instituição estabelecida socialmente tem papel fundamental na questão de prevenção da violência. As ações escolares refletem o que as crianças vivenciam externamente a elas. Isso mostra que parte da violência sofrida pelas crianças em seu âmbito familiar serão exacerbadas entre seus pares no interior da escola. Então, "[...] a violência familiar é um problema que traz dificuldades ao cotidiano escolar, uma vez que a escola não está imune a seus reflexos e a suas consequências" (LYRA; CONSTANTINO; FERREIRA, 2010 p. 153). Anteriormente já foi comentado sobre a violência escolar. Portanto, vale ressaltar as possíveis inadequação da dinâmica escolar, seja pelo despreparo de sua equipe profissional administrativo-pedagógica, seja pela 
fragilidade ou inexistência da rede de proteção, ou até mesmo pela forma como trata das diferenças e reproduz desigualdades.

Entretanto, torna-se evidente que a família, como primeira instituição social da vida de uma criança, e a escola como segunda, por sua interdependência, principalmente no que se refere ao desenvolvimento da criança, afetam-se mutuamente, influenciando uma à outra. De acordo com a Teoria Bioecológica do Desenvolvimento Humano (BRONFENBRENNER, 2011), o sujeito se constrói a partir de interações com os diversos ambientes e suas mudanças. A partir disso, pode-se considerar que o ser humano vive em constante aperfeiçoamento e mudanças influenciadas pelos diversos ambientes e pessoas com as quais se relaciona em seu processo de desenvolvimento humano.

Alguns períodos do desenvolvimento, tais como a infância e a adolescência, são considerados de maior influência e aprendizado. É neste momento que a família, a escola, a cultura e a sociedade demostram suas expectativas e exigências nas interações. Enfatiza-se, no processo de desenvolvimento humano e de prevenção das violências, a força das relações interpessoais, tanto na família como na escola. A qualidade das relações parentais é determinante para o estilo das relações sociais que a criança e o/a adolescente vão validar em sua vida.

\begin{abstract}
Um dos seus papéis principais é a socialização da criança, isto é, sua inclusão no mundo cultural mediante o ensino da língua materna, dos símbolos e regras de convivência em grupo, englobando a educação geral e parte da formal, em colaboração com a escola. Neste contexto, os recursos psicológicos, sociais, econômicos e culturais dos pais são aspectos essenciais para a promoção do desenvolvimento humano (POLONIA; DESSEN, 2005, p. 304).
\end{abstract}

Pode-se afirmar que o modelo das relações parentais é o exemplo determinante para o comportamento dos filhos em todas as etapas da vida. "O trabalho com os pais e a comunidade é particularmente importante para reduzir o risco da violência e do bullying a caminho e na volta da escola, assim como para reforçar o incentivo à não violência nas escolas" (UNESCO, 2019, p. 42). Estudos na área educacional mostram que o envolvimento dos pais nas atividades escolares e pessoais é fundamental no crescimento do desempenho escolar e na melhoria do relacionamento intrafamiliar (DESSEN; BIASOLI-ALVES, 2001; SOUZA, 2006; 2017). Isso sinaliza movimento para mudanças necessárias no dia a dia das famílias, bem como na dinâmica das relações no âmbito da escola. Há avanços nesse sentido e estímulos oficiais incentivando campanhas em favor do acompanhamento dos pais na vida de seus filhos, especialmente no que tange à relação família e escola, com o objetivo de reforçar a responsabilidade e a importância da família na sociedade, "[...] portanto, uma boa educação, baseada no amor, no respeito e na cooperação, fará com que as crianças tenham exemplos positivos a serem seguidos" (FANTE, 2005 p. 148).

Pelo exposto, o mesossistema família e escola deve ser fortalecido e dotado de políticas específicas, a fim de superar as situações de violência que ainda insistem em adentrar o ambiente escolar (ASINELLI-LUZ, 200o; SOUZA, 2006; 2016). Por meio do diálogo, da interação e reconhecimento da importância do desenvolvimento humano, há a reflexão sobre o trabalho em comunidades, em que o educador necessita aproximar-se da

Argum., Vitória, v. 12, n. 3, p. 211-221, set./dez. 2020. | ISSN 2176-9575 
família e do ambiente onde está inserido, despertando nos educandos o sentimento de pertencimento, da importância do vínculo/amor/afeto e da relevância da união de um grupo para a promoção de transformações. Para isso, o educador que está na comunidade necessita de formação de qualidade, para que seja possível a criação de estratégias de ação (FALEIROS; FALEIROS, 2011).

Na instituição escolar faz-se necessário superar a fragmentação da escola prazerosa e da escola assustadora. Para isso, é necessário ressignificar o Projeto Político Pedagógico desse espaço, pois é a centralidade para partir com as ações (fazer pensar, dialogar com outras possibilidades). Assim, o educador precisa inserir-se no coletivo e nas atividades da escola que contribuam para o andamento das atividades da instituição em parceria com a comunidade. Para Faleiros e Faleiros (2011), o espaço escolar é essencialmente privilegiado pela sua prática e construção cidadã, uma vez que em contato com os indivíduos e suas interações, ocorrem grandes oportunidades de discutir e garantir os direitos humanos fundamentais, pois há a troca de saberes e o respeito mútuo.

\section{Considerações finais}

O tema principal deste artigo é a integração da família e da escola em um ambiente permeado de violência. Entende-se família como sendo o primeiro contato social, o primeiro microssistema em que a criança entra em contato com o mundo. É por intermédio da família que o indivíduo passa a conhecer, adquirir e vivenciar culturas, costumes, crenças, orientação social e o afeto humano. Neste ambiente, a criança começa a se desenvolver de forma gradual e toda influência gerada é passível de permanecer no indivíduo.

O segundo ambiente impactante no que concerne ao desenvolvimento humano é a participação da criança no ambiente escolar. Neste microssistema, a criança passará a aprender sobre os conhecimentos culturalmente acumulados e sistematizados ao longo da história. Nele terá, prioritariamente, experiências sociais de inter-relação com outros indivíduos que não pertencem ao seu convívio familiar e comunitário. $\mathrm{Na}$ escola, as influências também são passíveis de permanência.

Família e escola são dois microssistemas específicos, mas que se integram entre si, em relação de interdependência, pois acompanham a criança, com maior ou menor intensidade, durante toda a vida. Infelizmente, a violência coabita esses dois ambientes afetando de forma significativa a vida da família e da escola. Como já citado, a violência é um fenômeno preocupante em nossa sociedade atual, pois cada vez mais observa-se a presença dela na vida de crianças, jovens e adultos. Surge dentro das famílias e das escolas sutilmente, por meio de abusos físicos e verbais, da negligência, violação de direitos, entre outros e que aparecem sem que lhes sejam dadas a devida importância. O modelo Bioecológico de Bronfenbrenner (2011) mostra a importância das influências do ambiente na vida dos seres humanos. Os componentes PPCT (pessoa, processo, contexto e tempo) caracterizam essa dinâmica que crianças, jovens e adultos vivenciam nos diferentes sistemas bioecológicos ao longo de suas vidas.

Argum., Vitória, v. 12, n. 3, p. 211-221, set./dez. 2020. | ISSN 2176-9575 
O impacto da violência acaba por criar alterações no desenvolvimento saudável do ser humano. Crianças e jovens que vivem situações de abusos em seus ambientes de maior contato sofrem consequências que são levadas ao longo de suas vidas e que poderiam ser evitadas. Família e escola devem andar juntas a fim de criarem uma relação harmoniosa e de minimizarem as situações de risco causadas pela violência. Saber disso é promissor para a prevenção da violência em relação à criança e ao adolescente, em especial os estudos no campo da neurobiologia, que ajudam a perceber e compreender as fobias, os medos, as somatizações, a irritabilidade. São saberes fundamentais que explicam o que acontece no cérebro da criança, se tornando um conhecimento essencial para o professor (RELVAS, 2017).

A prevenção precisa iniciar na infância, ocorrendo antes de um problema ser instaurado. É importante que seja contínua, natural, que oportunize o reconhecimento das características individuais do educando, destacando sua história, suas relações. Prevenção indica fortalecer vínculos com a família, escola e comunidade. É estimular a reflexão sobre o mundo que é apresentado (quais são as interações recíprocas, complexas entre um organismo humano biologicamente ativo e os objetos/símbolos dos ambientes). Desse modo, a revisão de literatura evidencia o quão importante são os estudos na área da Educação e suas relações entre família e as situações de violência, e que necessitam de aprofundamento e maior abrangência. Reforça-se que a família e a escola possuem necessária relação como fator de prevenção no processo educativo. Trata-se de enfatizar o cuidado com a educação humanizadora, de respeito ao educando e do seu processo de desenvolvimento cognitivo e socioemocional, podendo utilizar-se de mecanismos construídos pela Cultura de Paz e Educação para a Paz. É fundamental a continuidade de pesquisas nesse tema, bem como a criação de políticas de prevenção voltadas à família, à escola e à relação entre elas, incluindo a atenção às vítimas e agressores, uma vez que a relação entre a escola e a família oportunizam a formação dos sujeitos desde a infância, bem como segurança para enfrentar os desafios postos no decorrer da vida e que poderão influenciar em seu processo evolutivo. É preciso reforçar que o desenvolvimento pleno do ser dependerá da qualidade de suas relações, que, por sua vez, precisam ser respeitosas e humanizadoras.

\section{Referências}

ANTUNES, Deborah Christina; ZUIN, Antônio Álvaro Soares. Do Bullying ao preconceito: os desafios da barbárie à educação. Psicologia \& Sociedade, São Carlos, v. 20, n. 1. p. 33-42, 2008.

ASINELLI-LUZ, Araci. Educação e prevenção ao abuso de drogas: limites e possibilidades. 200o. Tese (Doutorado em Educação)-Faculdade de Educação da Universidade de São Paulo, São Paulo, 2000.

BRONFENBRENNER, Urie. Bioecologia do Desenvolvimento Humano: tornando os seres humanos mais humanos. Tradução: André de Carvalho Barreto. Porto Alegre: Artmed, 2011. 
DE ANTONI, Clarissa; KOLLER, Silvia Helena. Uma família fisicamente violenta: uma visão pela teoria bioecológica do desenvolvimento humano. Temas em Psicologia, Porto Alegre, v. 18, n. 1, p. 17-30, 2010.

DESSEN, Maria Auxiliadora Campos; BIASOLI-ALVES, Zélia Maria Mendes. O estudo da família como base para a promoção da tolerância. In: BIASOLI-ALVES, Zélia Maria Mendes; FISCHMANN, Roseli (Orgs.). Crianças e adolescentes: construindo uma cultura da tolerância. São Paulo: Editora da Universidade de São Paulo, 2001.

DESSEN, Maria Auxiliadora; POLONIA, Ana da Costa. A família e a escola como contextos de desenvolvimento humano. Paidéia, Ribeirão Preto, v. 17, n. 36, p. 2132, abr. 2007.

FALEIROS, Vicente de Paula; FALEIROS, Eva Silveira. Escola que protege: enfrentando a violência contra crianças e adolescentes. Brasília (DF): Ministério da Educação, Secretaria de Educação Continuada, Alfabetização e Diversidade, 2008.

FANTE, Cléo. Fenômeno bullying: como prevenir a violência nas escolas e educar para a paz. Campinas: Verus Editora, 2005.

LYRA, Gabriela Franco Dias; CONSTANTINO, Patrícia; FERREIRA, Ana Lúcia. Quando a violência familiar chega até a escola. In: ASSIS, Simone Gonçalves; CONSTANTINO, Patrícia; AVANCI, Joviana Quintes. (Orgs). Impactos da violência na escola: um diálogo com professores [online]. Rio de Janeiro: Ministério da Educação; Editora FIOCRUZ, 2010. Available from SciELO Books http://books.scielo.org . Acesso: jun. 2016.

LOPES NETO, Aramis. Bullying: comportamento agressivo entre estudantes. Jornal de Pediatra, Rio de Janeiro, v. 81, n. 5, p. 164-175, 2005.

LOURENÇO, Lélio Moura; SENRA, Luciana Xavier. A violência familiar como fator de risco para o bullying escolar: contexto e possibilidades de intervenção. Aletheia, Canoas, n. 37, p. 42-56, 2012.

MARCONDES, Keila Hellen Barbato; SIGOLO, Silvia Regina Ricco Lucato. Comunicação e envolvimento: Possibilidades de interconexões entre família-escola? Paidéia, São Paulo, v. 22, n. 51, p. 91-99, 2012.

MONTEIRO, Michelle Popenga Geraim. $O$ bullying segundo a percepção de estudantes do $5^{\circ}$ ano do ensino fundamental. 2017. Dissertação (Mestrado em Educação Profissional)-Setor de Educação da Universidade Federal do Paraná, Curitiba, 2017.

OLIVEIRA, Cynthia Bisinoto Evangelista de; MARINHO-ARAÚJO, Claisy Maria. A relação entre família e escola: intersecções e desafios. Estudos de Psicologia, Campinas, v. 27, n. 1, p. 99-108, 2010. 
POLONIA, Ana da Costa; DESSEN, Maria Auxiliadora. Em busca de uma compreensão das relações entre família escola. Psicol. esc. educ., Campinas, v. 9, n. 2, p. 303-312, dez. 2005 .

RELVAS, Marta Pires. A neurobiologia da aprendizagem para uma escola humanizadora: observar, investigar e escutar. Rio de Janeiro: Wak, 2017.

SALLES FILHO, Nei Alberto. Cultura de Paz e Educação para a Paz: olhares a partir da complexidade. Campinas: Papirus, 2019.

SILVA, Alissandra Calderaro Soares; ALENCAR, Josinára Ribeiro de; CHAMON, Edna Maria Querido de Oliveira; SOUZA, Marilza Terezinha Soares. Escola e família: contextos de desenvolvimento humano. Revista Ciências Humanas, São Paulo, v. 4, n. 1, p. 37-50, 2011.

SILVA, Ana Beatriz Barbosa. Mentes perigosas nas escolas: bullying. Rio de Janeiro: Objetiva, 2010.

SOUZA, Joelson Carvalho. O construto clima escolar e processos de vitimização entre pares. 2016. Dissertação (Mestrado em Educação)- Setor de Educação da Universidade Federal do Paraná, Curitiba, 2016.

SOUZA, Oralda Carlota Adur de. As representações de educadores sobre a aprendizagem de alunos que recebem acompanhamento da família. Dissertação (Mestrado em 2006)-Universidade Federal do Paraná, Curitiba, 2006.

SOUZA, Oralda Carlota Adur de. Família-Escola e desenvolvimento humano: um estudo sobre atitudes educativas familiares. Tese (Doutorado em 2017)-Universidade Federal do Paraná, Curitiba, 2017.

UNESCO. School Violence and bullying: global status report. International Symposium on School Violence and Bullying: From Evidence to Action, Seoul, Republic of Korea, 2019. 
Michelle Popenga Geraim MONTEIRO Trabalhou na concepção e delineamento ou análise e interpretação dos dados e; redação do artigo ou a sua revisão crítica.

Doutoranda em Educação pela UFPR (2018-2022). Mestra em Educação pela UFPR (2017). Especialista em Neuropedagogia pelo Instituto Rhema de Educação (2015). Graduação em Pedagogia pelo Centro Universitário Uninter (2012).

Tatiane Delurdes de LIMA-BERTON Trabalhou na concepção e delineamento ou análise e interpretação dos dados e; redação do artigo ou a sua revisão crítica.

Doutoranda em Educação (2018-2021) e Mestre em Educação (2015-2017) junto ao Programa de PósGraduação da Universidade Federal do Paraná na Linha Cognição, Aprendizagem e Desenvolvimento Humano, sob orientação da Professora Doutora Araci Asinelli da Luz. Graduada em Tecnologia em Gestão Pública pela Universidade Estadual do Oeste (UNICENTRO) (2018-2020). Especialista em Educação Integral Transformadora pela Faculdade Vicentina e Associação Gente de Bem, com patrocínio da Embaixada da Finlândia (2015-2017). Graduada em Pedagogia - Licenciatura Plena - pela Faculdade Cenecista de Campo Largo - FACECLA (Bolsista PROUNI) - voltado à formação de professores para o exercício das funções de magistério na Educação Infantil e nos anos iniciais do Ensino Fundamental e também para a docência da Educação de Jovens e Adultos e Gestão Educacional (2010-2014). Concluinte do Curso de Formação de Docentes (2007- 2010) para Educação Infantil e Ensino Fundamental - Séries Iniciais.

Araci ASINELLI-LUZ Trabalhou na aprovação da versão a ser publicada.

Graduada em História Natural pela Pontifícia Universidade Católica do Paraná (1969). Mestrado em Educação pela Universidade Federal do Paraná (1987). Doutorado em Educação pela Universidade de São Paulo (200o). Especialização em Ensino de Ciências, em Psicodrama Pedagógico e em Prevenção da Violência Doméstica contra criança e adolescente.

Argum., Vitória, v. 12, n. 3, p. 211-221, set./dez. 2020. | ISSN 2176-9575 